\title{
RATIO NILAI SOAKED DAN UNSOAKED CBR SUBGRADE TERHADAP TEBAL PERKERASAN RUNWAY BANDARA MALIKUSSALEH LHOKSEUMAWE
}

\author{
Said Jalalul Akbar \\ Jurusan Teknik sipil, Universitas Malikussaleh \\ Email: jaakidani@gmail.com
}

\begin{abstract}
Abstrak
Kekuatan runway dari sebuah bandara sangat bergantung oleh nilai CBR subgrade pada bandara tersebut. Nilai CBR subgrade bervariasi antara satu lokasi dengan lokasi lainnya. Dalam perencanaan perkerasan lentur (jalan atau runway) pemeriksaan terhadap nilai CBR subgrade soaked dan unsoaked perlu dilakukan sehubungan dengan keadaan di lapangan yang terkadang digenangi oleh air hujan. Penelitian ini bertujuan ingin mengetahui sejauh mana penurunan nilai CBR subgrade yang diakibatkan oleh genangan air terhadap nilai CBR tanpa genangan dan hubungannya dengan perencanaan tebal perkerasan. Metode yang digunakan adalah dengan cara pengambilan sample tanah di lapangan untuk diuji (test) nilai CBR di laboratorium dengan menggunakan alat test CBR. Pengujian dilakukan dengan dua cara yaitu test nilai CBR soaked dan nilai CBR unsoaked. Dari hasil penelitian diperoleh ratio nilai CBR subgrade soaked dan nilai CBR subgrade unsoaked adalah 5,64, yang berarti besarnya nilai CBR unsoaked 5,64 kali nilai CBR soaked. Tebal perkerasan total dengan menggunakan nilai CBR soaked adalah 412 $\mathrm{mm}$, sedangkan menggunakan nilai $\mathrm{CBR}$ unsoaked adalah $247 \mathrm{~mm}$. Perbedaan nilai CBR subgrade diatas (5,64 kali nilai CBR soaked)) menghasilkan perbedaan nilai total tebal perkerasan yang besar pula ( 412 $\mathrm{mm} / 247 \mathrm{~mm}=1,67$ ). Ternyata nilai CBR subgrade pada sebuah runway harus memiliki nilai kualitas yang tinggi dan sesuai dengan beban (pesawat) yang dilayani pada bandara tersebut.
\end{abstract}

Kata kunci: Ratio, CBR soaked,CBR unsoaeked

\section{Pendahuluan}

Nilai California Bearing Rasio (CBR) subgrade merupakan salah satu faktor yang sangat mempengaruhi tebal atau tipisnya perkerasan lentur/kaku dari sebuah kostruksi jalan atau landas pacu (runway). Nilai CBR subgrade sangat bervariasi dan tergantung dari jenis tanah pada suatu lokasi yang akan dibangun sebuah konstruksi jalan/landas pacu. Jika tanah pada sebuah lokasi yang akan dibangun sebuah konstruksi jalan/landas pacu tidak memenuhi nilai CBR sesuai yang diinginkan (tidak memenuhi syarat), tanah tersebut dapat dilakukan perbaikan atau diganti dengan tanah yang memenuhi syarat yang didatangkan dari lokasi lain.

Nilai CBR subgrade juga dipengaruhi oleh keadaan cuaca seperti turunnya hujan. Saat turun hujan air akan masuk ke dalam lapisan tanah dasar pada konstruksi. Banyaknya air yang masuk (diresapi) ke dalam lapisan tanah dasar tergantung pada intensitas hujan dan durasi hujan, hingga pada suatu keadaan lapisan tanah dasar digenangi oleh air hujan dan lapisan tanah dasar menjadi jenuh yang diakibatkan oleh genangan tersebut. Saat dalam keadaan tergenangi oleh air 
tentu mempengaruhi kepada penurunan nilai CBR subgrade yang berarti menurunkan daya dukung tanah tersebut.

Adapun yang menjadi permasalahan dalam penelitian ini adalah perbedaan (perbandingan) nilai CBR soaked dengan nilai CBR unsoaked yang merupakan nilai yang akan mempengaruhi terhadap perencanaan tebal perkerasan nantinya. Penelitian ini bertujuan ingin mengetahui sejauh mana penurunan nilai CBR subgrade yang diakibatkan oleh genangan air terhadap nilai CBR tanpa genangan dan hubungannya dengan perencanaan tebal perkerasan. Penelitian ini berlokasi pada runway bandara Malikussaleh Lhokseumawe, Kabupaten Aceh Utara.

Metode yang digunakan pada penelitian ini adalah dengan cara pengambilan sample tanah di lapangan untuk diuji (test) nilai CBR di laboratorium dengan menggunakan alat test CBR. Pengujian dilakukan dengan dua cara yaitu test nilai CBR soaked dan nilai CBR unsoaked. Penelitian ini hanya dibatasi pada pemeriksaan nilai CBR laboratorium saja yang merupakan pedoman (acuan) saat pelaksanaan di lapangan.

\section{Tinjauan Kepustakaan}

\subsection{Material}

Untuk sebuah konstruksi jalan baik itu jalan raya maupun runway pada bandara secara umum digunakan beberapa material seperti agregat kasar (coarse aggregate), agregat halus (fine aggregate), pasir (sand), dan filler (dust) serta bahan pengikat aspal (asphalt).

Oglesby dan Hick (1982), menyatakan bahwa bahan yang paling umum untuk lapisan jalan (runway) dan strukturnya adalah batu pecah, batu kerikil yang dipecah dan pasir. Sukirman (1999) menyatakan bahwa gradasi agregat merupakan distribusi partikel-partikel agregat berdasarkan ukuran dan merupakan hal penting dalam menentukan stabilitas perkerasan. Spesifikasi campuran dari gradasi rapat tipe IV diperlihatkan pada Tabel 1

Tabel 1 Spesifikasi Agregat Bergradasi Rapat Tipe IV

\begin{tabular}{|c|c|c|c|}
\hline No. & Saringan & Ukuran $(\mathbf{m m})$ & Persen lolos (\%) \\
\hline 1. & $3 / 4^{\prime}$ & 19,05 & 100 \\
\hline 2. & $1 / 2^{“}$ & 12,7 & $80-100$ \\
\hline 3. & $3 / 8^{\prime}$ & 9,52 & $70-90$ \\
\hline 4. & No. 4 & 4,76 & $50-70$ \\
\hline 5. & No. 8 & 2,38 & $35-50$ \\
\hline 6. & No. 30 & 0,59 & $18-28$ \\
\hline 7. & No. 50 & 0,279 & $13-23$ \\
\hline 8. & No. 100 & 0,149 & $8-16$ \\
\hline 9. & No. 200 & 0,074 & $4-10$ \\
\hline
\end{tabular}

Sumber: Dairi, 1995

Menurut Krebs dan Walker (1971), gradasi merupakan kunci utama dari sifat-sifat agregat. Berbagai macam metode dalam menyatakan distribusi ukuran agregat telah ditemukan. Salah satu dari metode tersebut adalah dengan menggunakan Rumus Fuller yaitu: 


$$
P=100(d / D)^{n}
$$

Keterangan :

$\mathrm{P}=$ Persen lolos saringan

$\mathrm{d}=$ Ukuran agregat yang sedang diperhitungkan

$\mathrm{D}=$ Ukuran maksimum dari agregat

$\mathrm{n}=$ Koefisien $(0,45-0,5$ untuk gradasi menerus $)$

\subsection{Pengujian Material}

Menurut Final Report Consultant (2003), material yang digunakan terdiri dari agregat kasar (coarse aggregate), agregat halus (fine aggregate), pasir (sand), porland cement (PC) dan aspal. Pengujian terhadap material akan diperoleh hasil sebagai berikut :

1. Pemeriksaan sifat-sifat fisik agregat dan aspal harus memenuhi syarat sesuai dengan ketentuan AASHTO.

2. Hasil analisa saringan terhadap agregat harus memenuhi spesifikasi yang ditetapkan.

\subsection{Kepadatan dan Daya Dukung Tanah}

Menurut Sukirman (1999), beban kendaraan yang dilimpahkan ke lapisan perkerasan melalui roda-roda kendaraan selanjutnya disebarkan ke lapisan-lapisan di bawahnya dan akhirnya diterima oleh tanah dasar. Dengan demikian tingkat kerusakan konstruksi perkerasan selama masa pelayanan tidak saja ditentukan oleh kekuatan dari lapisan perkerasan tetapi juga tanah dasar. Daya dukung tanah dasar dipengaruhi oleh jenis tanah, tingkat kepadatan, kadar air, kondisi drainase dan lain-lain. Tanah dengan tingkat kepadatan tinggi mengalami perubahan kadar air kecil dan mempunyai daya dukung yang lebih besar jika dibandingkan dengan tanah sejenis yang tingkat kepadatannya lebih rendah. Tingkat kepadatan dinyatakan dalam persentase berat volume kering $(\not k)$ tanah terhadap berat volume kering maksimum $\left(\not k_{\text {maks }}\right)$.

Pemeriksaan dilakukan dengan menggunakan pemeriksaan kepadatan standard (Standard Proctor) sesuai dengan AASHTO T99-74 atau PB-0111, atau dengan menggunakan pemeriksaan kepadatan berat (Modified Proctor) sesuai AASHTO T180-7 atau PB-0112-76. Daya dukung tanah dasar pada perencanaan perkerasan lentur dinyatakan dengan nilai CBR (California Bearing Ratio). CBR pertama kali diperkenalkan oleh California Division of Highways pada tahun 1928 (Sukirman, 1999).

CBR adalah perbandingan antara beban yang dibutuhkan untuk penetrasi contoh tanah sebesar 0,1" / 0,2" dengan beban yang ditahan batu pecah standar pada penetrasi 0,1" / 0,2" tersebut. Harga CBR dinyatakan dalam persen. Jadi harga CBR adalah nilai yang menyatakan kualitas tanah dasar dibandingkan dengan bahan standar berupa batu pecah yang mempunyai nilai CBR sebesar $100 \%$ dalam memikul beban lalu lintas.

\subsection{Penentuan CBR}

Menurut Sukirman (1999), alat percobaan untuk menentukan besarnya CBR berupa alat yang mempunyai piston dengan luas 3 inch $^{2}$. Piston digerakkan 
kecepatan 0,05 inch/menit, vertikal ke bawah. Proving ring digunakan untuk mengukur beban yang dibutuhkan pada penetrasi tertentu yang diukur dengan arloji pengukur (dial). Beban yang dipergunakan untuk melakukan penetrasi bahan standar diperlihatkan pada Tabel 2.

Tabel 2 Besarnya beban dipergunakan dibutuhkan untuk melakukan Penetrasi bahan standar

\begin{tabular}{|c|c|c|}
\hline$\frac{\text { Pentrasi }}{\text { Inch }}$ & $\frac{\text { Beban Standar }}{\text { Ibs }}$ & $\frac{\text { Beban Standar }}{\text { Ibs/inch }^{2}}$ \\
\hline 0,1 & 3000 & 1000 \\
0,2 & 4500 & 1500 \\
0,3 & 5700 & 1900 \\
0,4 & 6900 & 2300 \\
0,5 & 7800 & 6000 \\
\hline
\end{tabular}

Sumber : Sukirman (1999)

Dari grafik hubungan antara beban dan penetrasi pada pemeriksaan CBR, jika lengkung yang diperoleh awal lengkung merupakan garis lurus maka :

$$
\begin{aligned}
& C B R_{0,1^{\prime \prime}}=x / 3000 x 100 \%=a \% \\
& C B R_{0,2^{\prime \prime}}=x / 4500 x 100 \%=b \%
\end{aligned}
$$

Nilai CBR adalah nilai yang terbesar antara (4) dan (5), jika lengkung diperoleh seperti lengkung 2 (awal lengkung merupakan cekung ) maka :

$$
\begin{aligned}
& C B R_{01^{\prime \prime}}=x_{1} / 3000 \times 100 \%=a_{1} \% \\
& C B R_{02^{\prime \prime}}=y_{1} / 4500 \times 100 \%=b_{1} \%
\end{aligned}
$$

Nilai CBR adalah yang terbesar antara $\mathrm{a}_{1}$ dan $\mathrm{b}_{1}, \mathrm{x}_{1}$ dan $\mathrm{y}_{1}$ diperoleh dari langkah-langkah sebagai berikut:

1. Garis singgung ditarik pada garis lengkung sehingga memotong sumbu absis.

2. Titik yang menunjukkan penetrasi 0,1 " dan 0,2 " digeser.

\subsubsection{CBR Lapangan}

Sukirman (1999) menyatakan bahwa CBR Lapangan sering disebut CBR inplace atau field CBR yang gunanya untuk :

a. Mendapatkan nilai CBR asli di lapangan, sesuai dengan kondisi tanah dasar saat itu namun digunakan untuk perencanaan tebal lapisan perkerasan yang lapisan tanah dasarnya sudah tidak akan dipadatkan lagi. Pemeriksaan dilakukan dalam kondisi kadar air tanah tinggi (musim penghujan) atau dalam kondisi terburuk yang mungkin terjadi.

b. Untuk mengontrol apakah kepadatan yang diperoleh sudah sesuai dengan yang diinginkan. Pemeriksaan untuk tujuan ini.tidak umum digunakan, lebih sering menggunakan pemeriksaan yang lain seperti sand cone dan lain-lain. 


\subsubsection{CBR Rencana}

CBR rencana disebut juga CBR laboratorium atau design CBR. Tanah dasar (subgrade) pada kontruksi jalan baru merupakan tanah asli, tanah timbunan, atau tanah galian yang sudah dipadatkan sampai mencapai kepadatan 95\% kepadatan maksimum. Dengan demikian daya dukung tanah dasar tersebut merupakan nilai kemampuan lapisan tanah memikul beban setelah tanah tersebut dipadatkan. Berarti nilai CBRnya adalah nilai CBR yang diperoleh dari contoh tanah yang dibuatkan mewakili tanah tersebut setelah dipadatkan. CBR ini disebut CBR rencana titik dan karena disiapkan di laboratorium, disebut juga CBR laboratorium (Sukirman, 1999). CBR laboratorium dapat dibedakan atas 2 macam yaitu CBR laboratorium rendaman (soaked design CBR) dan CBR laboratorium tanpa rendaman (unsoaked design $\mathrm{CBR}$ ).

\subsection{Pemadatan Laboratorium}

Bowles (1991) menjelaskan bahwa pemadatan merupakan usaha untuk mempertinggi kerapatan material dengan pemakaian energi mekanis untuk menghasilkan pemampatan partikel.Di laboratorium benda uji untuk mendapatkan pengendalian mutu, dipadatkan dengan menggunakan daya tumbukan atau dinamik, alat penekan, atau tekanan statik yang menggunakan piston dan mesin tekanan.

Selanjutnya Ismail (1995) menyajikan formula untuk menghitung energi tumbukan yaitu :

$$
C E=b . t . j \frac{1}{v}
$$

Keterangan :

$\mathrm{b}=$ berat penumbuk (hammer), $\mathrm{kg}$

$\mathrm{t}=$ tinggi jatuh penumbuk hammer, $\mathrm{m}$

$\mathrm{j}=$ jumlah tumbukan perlapisan

$1=$ jumlah lapisan

$\mathrm{v}=$ volume tabung cetak (mold), $\mathrm{m}^{3}$

\subsection{Perkerasan Lentur (Flexible Pavement)}

Perkerasan berfungsi sebagai tumpuan rata-rata, permukaan yang rata menghasilkan jalan pesawat yang stabil dan ditinjau dari fungsinya harus dijamin bahwa tiap-tiap lapisan dari atas ke bawah cukup kekerasan dan ketebalannya sehingga tidak mengalami perubahan karena tidak mampu menahan beban (Ashford dan Wright, 1979).

Perkerasan lentur terdiri dari lapisan permukaan, lapisan pondasi, dan lapisan pondasi bawah, masing-masing bisa satu lapis atau lebih. Semuanya digelar di atas tanah asli yang dipadatkan yang disebut subgrade, subgrade bisa terletak di atas timbunan atau galian. Lapisan permukaan terdiri dari campuran aspal dan agregat, mempunyai rentang ketebalan $5 \mathrm{~cm}$ atau lebih. Fungsi utamanya adalah untuk memberikan permukaan yang rata dan operasi lalu lintas yang aman, untuk memikul beban yang bekerja serta menyebarkan beban tersebut ke lapisan-lapisan di bawahnya (Basuki, 1986). 
Menurut Basuki (1986), ada beberapa metode dalam perencanaan perkerasan bandara antara lain :

- Metode US Coorporation of Engineers, lebih dikenal dengan metode CBR.

- Metode Federal Aviation Administration (FAA)

- Metode Load Classification Number (LCN)

- Metode Asphalt Institute

- Metode Canadian Department of Transformation

Menurut Basuki (1989), dalam merencanakan tebal perkerasan total di atas subgrade berdasarkan nilai CBR dapat digunakan metode US Corps Of Engineers dengan menggunakan rumus empiris sebagai berikut :

$$
\mathrm{T}=(8.71 \log \mathrm{R}+5.43) \sqrt{P \frac{1}{8.1 C B R}-\frac{1}{450 . S}}
$$

di mana :

$$
\begin{aligned}
& \mathrm{T}=\text { Tebal perkerasan total }(\mathrm{mm}) \text { di atas subgrade } \\
& \mathrm{R}=\text { Jumlah ESWL yang bekerja (beban repetisi) } \\
& \mathrm{S}=\text { Tekanan roda }(\text { ban) dalam Mpa } \\
& \mathrm{P}=\mathrm{ESWL} \text { dalam } \mathrm{Kg}
\end{aligned}
$$

Untuk membedakan lapisan-lapisan perkerasan digunakan koefisien faktor equivalent material dari AASHTO, di mana masing-masing koefisien faktor equivalent material dibandingkan satu sama lain sehingga nantinya hasil perbandingan tersebut dikalikan dengan tebal masing-masing lapisan. Tebal lapisan base diperoleh berdasarkan hasil perhitungan tebal perkerasan total di atas subgrade (persamaan 7) dikurangi dengan hasil perbandingan masing-masing lapisan. Koefisien faktor equivalent material diperlihatkan pada Tabel 3

Tabel 3 Koefisien Faktor Equivalent Material

\begin{tabular}{|l|c|}
\hline Material & Koefisien \\
\hline Beton aspal (AC) & 0.017 \\
Batu pecah atau kerikil (CSB)= Crushed Stone base) & 0.0055 \\
Cement treated base (CTB) & 0.091 \\
\hline
\end{tabular}

Sumber: Basuki (1986)

\section{Metode Penelitian}

\subsection{Peralatan}

Peralatan yang digunakan dalam penelitian ini ialah peralatan untuk pemadatan (compactor) dengan menggunakan alat standard proctor untuk mendapatkan kadar air optimum dan $\gamma_{\mathrm{k}}$ tanah maksimum, kemudian pemeriksaan kepadatan berat (Modified Proctor) sesuai AASHTO T180-74 atau PB-0112-76. Pengujian tersebut diperlukan untuk mendapatkan nilai CBR tanah dasar (subgrade) yang contoh tanahnya diambil dari daerah pinggiran landas pacu yang dianggap mewakili tanah dibawah lapisan perkerasan landas pacu pada bandara Malikussaleh Lhokseumawe. Pengujian dilakukan di Laboratium Transportasi Fakultas Teknik Universitas Syiah Kuala Darussalam Banda Aceh. 


\subsection{Pengumpulan data}

Data yang diperlukan sebagai data utama adalah data hasil penelitian di laboratorium yaitu data CBR tanah dasar. Data pendukung seperti spesifikasi bandara, spesifikasi pesawat dan jenis pesawat yang dilayani yang merupakan data untuk menghitung tebal perkerasan runway diambil dari bandara tersebut.

Bandara Malikussaleh Lhokseumawe Aceh Utara adalah bandara yang dibangun oleh Pertamina dan kepemilikannya ada pada PT. Arun NGL dengan panjang landasan pacu (runway) $1850 \mathrm{~m}$ dan lebarnya $30 \mathrm{~m}$. Bandara Malikussaleh melayani penerbangan perusahaan PT. Arun yang menggunakan jenis pesawat terbang Beach Craft dengan kapasitas penumpang 20 orang dan pesawat terbang jenis DAS 7 dengan kapasitas penumpang 40 orang. Klasifikasi bandara Malikussaleh termasuk dalam katagori kelas C. Sejak tahun Maret 2004 bandara Malikussaleh mulai melayani penerbangan komersial sipil yang dilaksanakan oleh operator penerbangan sipil Jatayu yang menggunakan pesawat terbang jenis Boeing 737 A 100 dengan kapasitas penumpang 100 orang. Di samping itu bandara Malikussaleh juga melayani penerbangan militer dengan menggunakan pesawat Hercules.

Pengujian yang dilakukan untuk memperoleh nilai CBR tanah dasar adalah sebagai berikut, contoh tanah diambil dari pinggir landas pacu yang dianggap representatif dari tanah dasar yang digunakan pada struktur landas pacu bandara tersebut dan pengambilan contoh tanah 2 titik. Jarak kedua titik tersebut terhadap panjang runway 500 meter dan jarak antara titik tersebut dengan sisi memanjang runway 2 meter. Kemudian dilakukan pengujian kepadatan menggunakan alat modified proctor. Pengujian ini diperlukan untuk mendapatkan kadar air optimum dan gama kering tanah maximum. Pengujian kepadatan menggunakan mold dengan diameter 4" dan tinggi 4,584". Contoh tanah dari lapangan dikeringkan dahulu hingga gembur, kemudian dihancurkan dan disaring dengan menggunakan saringan no. $4(4,75 \mathrm{~mm})$. Benda uji masing-masing titik dibagi menjadi 5 bahagian, tiap-tiap bagian dicampur dengan air yang ditentukan dan diaduk sampai merata. Benda uji dimasukkan kedalam plastik dan disimpan selama 12 jam agar kadar air merata pada seluruh bahagian tanah. Pemadatan dilakukan dengan alat penumbuk modified 4,54 kg (10 lbs) dengan tinggi jatuh 45,7 cm (18”). Tanah dipadatkan dalam 5 lapisan dan tiap-tiap lapisan dipadatkan 25 tumbukan. Penentuan kadar air (w) dari benda uji mengikuti (sesuai) PB-0210-76 sedangkan pengujian (pemeriksaan) kepadatan berat dilakukan berdasarkan AASHTO T-180-74 atau PB-0112-76.

Selanjutnya dipersiapkan tanah untuk benda uji CBR dengan memadatkan dalam mold CBR dengan diameter 6", tinggi 7". Pemadatan dilakukan dengan menggunakan alat penumbuk modified $4,54 \mathrm{~kg}$ dengan tinggi jatuh $45,7 \mathrm{~cm}$ (sesuai dengan cara pemriksaan kepadatan PB-0112-76). Pemadatan dilakukan pada kadar air optimum yang diperoleh dan masing-masing titik dibuat 4 benda uji, yaitu 2 benda uji Untuk CBR rendaman dan 2 benda uji dibuat untuk CBR tanpa rendaman. Contoh tanah yang sudah dipadatkan permasing-masing titik diambil 2 contoh dari tiap titik kemudian direndam selama 2x24 jam. Selanjutnya dilakukan pengujian penetrasi dengan menggunakan mesin penetrasi berkapasitas 
4,45 ton (10000 lbs) dengan kecepatan penetrasi 1,27 mm per menit, sehingga diperoleh nilai CBR tanah dasar.

\subsection{Pengolahan data}

Nilai CBR tanpa rendaman hasil dari pengujian akan dibandingkan dengan nilai CBR rendaman untuk mendapatkan ratio dari kedua perbandingan tersebut, kemudian dilakukan perhitungan tebal perkerasan dengan menggunakan nilai CBR rendaman dan tanpa rendaman. Hasil dari perhitungan tersebut akan dilakukan perbandingan-perbandingan untuk melihat variasi dari tebal perkerasan.

\section{Hasil dan Pembahasan}

\subsection{Hasil}

Berdasarkan pengujian yang telah dilakukan di laboratorium, maka diperoleh nilai CBR dari masing-masing titik sebagai berikut:

Tabel 4 Hasil Pengujian CBR Rendaman

\begin{tabular}{|c|c|c|c|c|}
\hline $\begin{array}{c}\text { Titik } \\
\text { sample }\end{array}$ & $\begin{array}{c}\text { W Optimum } \\
(\mathbf{\%})\end{array}$ & $\begin{array}{c}\boldsymbol{\mu d} \\
(\mathbf{g r a m} / \mathbf{c m})\end{array}$ & $\begin{array}{c}\text { Nomor } \\
\text { sample }\end{array}$ & $\begin{array}{c}\text { CBR } \\
\mathbf{( \% )}\end{array}$ \\
\hline C & 13,00 & 1,868 & C1S & 16,20 \\
C & 13,00 & 1,868 & C2S & 18,60 \\
D & 12,23 & 1,970 & D1S & 18,10 \\
D & 12,23 & 1,970 & D2S & 15,20 \\
\hline
\end{tabular}

Note: $\mathrm{S}$ adalah Soaked (Rendaman)

Tabel 5 Hasil Pengujian CBR Tanpa Rendaman

\begin{tabular}{|c|c|c|c|c|}
\hline $\begin{array}{c}\text { Titik } \\
\text { Sample }\end{array}$ & $\begin{array}{c}\text { W Optimum } \\
\mathbf{( \% )}\end{array}$ & $\begin{array}{c}\boldsymbol{\mu d} \\
(\mathbf{g r a m} / \mathbf{c m})\end{array}$ & $\begin{array}{c}\text { Nomor } \\
\text { Sample }\end{array}$ & $\begin{array}{c}\text { CBR } \\
\mathbf{( \% )}\end{array}$ \\
\hline C & 13,00 & 1,868 & C1US & 94,30 \\
C & 13,00 & 1,868 & C2US & 93,30 \\
D & 12,23 & 1,970 & D1US & 89,50 \\
D & 12,23 & 1,970 & D2US & 85,70 \\
\hline
\end{tabular}

Note: US adalah Unsoaked (Tanpa Rendaman)

a. Ratio nilai CBR subgrade soaked dan unsoaked

$\mathrm{CBR}$ ratio $=$ Nilai CBR unsoaked terkecil $/$ Nilai CBR soaked terkecil

$\mathrm{CBR}$ ratio $=85,70 \% / 15,20 \%=5,64 \%$

b. Perhitungan tebal perkerasan total

Dengan menggunakan nilai CBR soaked terkecil

$\mathrm{T}=(8.71 \log \mathrm{R}+5.43) \sqrt{P \frac{1}{8.1 C B R}-\frac{1}{450 . S}}$

$\mathrm{T}=(8.71 \log 18250+5.43) \sqrt{20203 \frac{1}{8,1.15,4}-\frac{1}{450.0,7}}$

$\mathrm{T}=412 \mathrm{~mm}$ 
Dengan menggunakan nilai CBR unsoaked terkecil

$$
\begin{aligned}
& \mathrm{T}=(8.71 \log 18250+5.43) \sqrt{20203 \frac{1}{8,1.85,7}-\frac{1}{450.0,7}} \\
& \mathrm{~T}=247 \mathrm{~mm}
\end{aligned}
$$

\subsection{Pembahasan}

Pada perhitungan nilai ratio CBR subgrade di atas digunakan nilai CBR terkecil dari ke 4 sample dari masing-masing titik. Hal ini dikarenakan dalam pelaksanaan di lapangan biasanya untuk mendisain tebal perkerasan sering diambil nilai CBR terendah dari nilai CBR yang dihasilkan dari beberapa benda uji dan biasa diambil dari benda uji soaked. Pengambilan nilai tersebut dengan asumsi bahwa saat terjadinya hujan atau genangan air hujan, akan menyebabkan lapisan tanah dasar terendam oleh air sehingga daya dukung tanah dasar (nilai CBR) akan terjadi penurunan nilai. Penggunaan nilai CBR subgrade yang nilainya terkecil (pada perencanaan tebal perkerasan) dari beberapa sample hasil pengujian laboratorium bertujuan agar kekuatan konstrusi jalan menjadi aman dari beban yang berkerja pada jalan tersebut nantinya. Jika nilai CBR kecil akan menghasilkan lapis tebal perkerasan semakin besar (tebal).

Berdasarkan perhitungan di atas diperoleh ratio nilai CBR subgrade, antara nilai CBR soaked dengan nilai CBR unsoaked sebesar 5,64 yang berarti besarnya nilai CBR unsoaked 5,64 kali lebih besar dari nilai CBR soaked. Dari perbandingan yang didapatkan terlihat bahwa untuk merencanakan tebal perkerasan dengan menggunakan nilai CBR unsoaked, harus menggunakan 5,64 kali nilai CBR soaked. Pada perhitungan tebal perkerasan total di atas juga terlihat bahwa nilai tebal perkerasan total dengan menggunakan nilai CBR soaked adalah $412 \mathrm{~mm}$, sedangkan menggunakan nilai CBR unsoaked adalah $247 \mathrm{~mm}$. Ternyata perbedaan nilai CBR di atas 5,64 kali nilai CBR soaked, menghasilkan perbedaan nilai total tebal perkerasan yang besar pula $(412 \mathrm{~mm} / 247 \mathrm{~mm}=1,67)$. Sebagaimana diketahui bahwa dalam merencanakan tebal perkerasan jalan raya semakin besar nilai CBR yang digunakan semakin tipis tebal lapisan perkerasan yang dibutuhkan, sebaliknya semakin kecil nilai CBR yang digunakan semakin besar (tebal) lapisan perkerasan yang dibutuhkan.

Pada tabel di atas juga terlihat bahwa nilai CBR terbesar unsoaked hampir mencapai nilai CBR maximum yaitu 94,30\% (CBR $\max =100 \%)$. Dapat dikatakan bahwa nilai CBR subgrade untuk sebuah runway (landas pacu) memiliki nilai kualitas yang tinggi dan sesuai dengan beban (pesawat) yang dilayani. Perencanaan tebal perkerasan runway sangat berpengaruh kepada jenis pesawat (besar atau kecil) yang akan dilayani dan besarnya repetisi beban (beban pengulangan) pada bandara tersebut.

\section{Kesimpulan dan Saran}

\subsection{Kesimpulan}

Berdasarkan hasil penelitian dan pembahasan maka dapat diambil kesimpulan sebagai berikut: 
1. Ratio nilai CBR subgrade soaked dan nilai CBR subgrade unsoaked adalah 5,64 yang berarti besarnya nilai CBR unsoaked 5,64 kali nilai CBR soaked.

2. Tebal perkerasan total dengan menggunakan nilai CBR soaked adalah 412 mm, sedangkan menggunakan nilai CBR unsoaked adalah $247 \mathrm{~mm}$, perbedaan nilai CBR subgrade di atas 5,64 kali nilai CBR soaked menghasilkan perbedaan nilai total tebal perkerasan yang besar pula (412 $\mathrm{mm} / 247 \mathrm{~mm}=1,67$ ).

3. Nilai CBR subgrade pada sebuah runway harus memiliki nilai kualitas yang tinggi dan sesuai dengan beban (pesawat) yang dilayani pada bandara tersebut.

\subsection{Saran}

Dalam melakukan penelitian yang berhubungan dengan pemeriksaan nilai CBR subgrade di laboratorium, pengambilan sample tanah di lapangan harus sesuai dengan panjang/luas lokasi yang akan diteliti, agar keakuratan data hasil pengujian lebih mendekati kebenaran.

\section{Daftar Kepustakaan}

1. AASHTO, 1990, Standard Spesification for Transportation Materials and Methods of Sampling and Testing, $15^{\text {th }}$ ed. Washington, D.C

2. Anonim, 2003, Final Report Consultant, Fakultas Teknik Universitas Syiah Kuala, Banda Aceh

3. Ashford, N and Paul H.Wright, 1979, Airport Engineering, John Wiley and Sons Inc, Canada

4. Basuki, H, 1986, Merancang Merencanakan Bandara, Penerbit Alumni, Bandung

5. Bowless, 1991, Mekanika Tanah, Erlangga, Jakarta

6. Dairi G, 1995, Bahan Perkerasan Jalan. Badan Penelitian dan Pengembangan Departemen Pekerjaan Umum, Jakarta

7. Ismail, M.A, 1995, Petunjuk Praktikum Mekanika Tanah, Penerbit Fakultas Teknik Unsyiah, Banda Aceh

8. Krebs, R.D and Walker, R.D., 1971, Highway Materials, Mc Graw Hill Inc., USA

9. Oglesby, C.H.and R.G. Hick, 1982, Highway Engineering, $4^{\text {th }}$ ed. Willey and Sons, New York

10. Sukirman, S., 1999, Perkerasan Lentur Jalan Raya, Penerbit Nova, Bandung 